\title{
Addendum
}

\section{Highly Convenient, One-Pot Synthesis of Nitriles from Aldehydes Using the $\mathrm{NH}_{2} \mathrm{OH} \cdot \mathrm{HCl} / \mathrm{NaI} / \mathrm{MeCN}$ System}

Roberto Ballini,* Dennis Fiorini, Alessandro Palmieri Synlett 2003, 1841.

The authors have found that the reported procedure for the conversion of aromatic aldehydes into nitriles leads to poorly reproducible results. The new procedure involves the utilization of DMF as solvent and 4 equivalents of NaI at reflux. The general method for conversion of aromatic aldehydes and the corrected yields of the obtained nitriles follow.

\section{General Procedure for the One-Pot Preparation of Aryl Nitriles}

To a stirred heterogeneous mixture of $\mathrm{NH}_{2} \mathrm{OH} \cdot \mathrm{HCl}(1.3 \mathrm{mmol})$ and $\mathrm{NaI}(4 \mathrm{mmol})$ in DMF (4 mL), aldehyde $\mathbf{1}(1 \mathrm{mmol})$ was added at room temperature. The reaction mixture was refluxed for $6 \mathrm{~h}$, then was allowed to cool and was poured into cold $1 \mathrm{~N} \mathrm{HCl}(10 \mathrm{~mL})$. After extraction with $\mathrm{Et}_{2} \mathrm{O}(3 \times 10 \mathrm{~mL})$, the combined organic layers were dried $\left(\mathrm{Na}_{2} \mathrm{SO}_{4}\right)$, filtered, and concentrated under vacuum. The crude nitrile was purified by flash chromatography to give the pure compound 2.
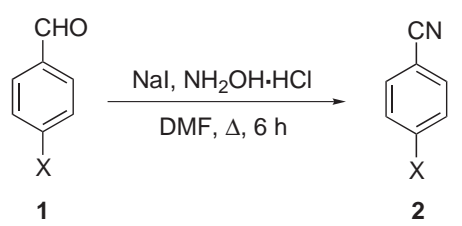

\begin{tabular}{cc}
\hline $\mathrm{X}$ & Yield (\%) of $\mathbf{2}$ \\
\hline $\mathrm{H}$ & 70 \\
$\mathrm{MeO}$ & 82 \\
$\mathrm{Me}$ & 76 \\
$\mathrm{NO}_{2}$ & 83 \\
\hline
\end{tabular}

